\title{
Tasa de erradicación y resistencia al tratamiento para infección por helicobacter pylori en pacientes del Hospital Apoyo- Pichanaki en el año 2018.
}

Eradication rate and treatment resistance for infection by helicobacter pylori in patients of the Hospital Apoyo-Pichanaki in the year 2018.

Edith Ysabel Leonardo Reyes ${ }^{1, a}$, Lucia Erika Uscuvilca Ramirez ${ }^{1, a}$, Monica Alejandra Calle Vilca ${ }^{1, b}$

\section{RESUMEN}

Objetivo: Evaluar la tasa de erradicación y resistencia bacteriana al tratamiento para infección por Helicobacter pylori en pacientes del Hospital Apoyo-Pichanaki, en el año 2018. Material y métodos: Corresponde a un estudio descriptivo, retrospectivo y de corte transversal, empleándose una muestra de 327 historias clínicas de pacientes con infección por Helicobacter pylori, de enero a diciembre del 2018, empleándose la técnica de análisis documental y el instrumento la ficha de registro de datos. Resultados: La tasa de erradicación para infección por Helicobacter pylori en pacientes del Hospital Apoyo-Pichanaki fue del 91,4\%, con régimen terapéutico óptimo de primera línea con claritromicina $500 \mathrm{mg}$, amoxicilina $1 \mathrm{~g}$ y omeprazol $20 \mathrm{mg}$ cada 12 horas por 14 días, siendo la mayor tasa de erradicación en el sexo femenino con $60,9 \%$ y solo un $39.1 \%$ en el sexo masculino. La mayor resistencia bacteriana fue $25 \%$ para edades de 44 a 48 años y de sexo femenino, se encontró un 8,6\% de resistencia bacteriana. Conclusiones: Se ha encontrado una tasa de erradicación para Helicobacter pylori del $91,4 \%$, y un 8,6 \% de resistencia bacteriana a la primera y segunda línea de tratamiento utilizados para la erradicación de la infección.

PALABRAS CLAVE: Tasa de erradicación, resistencia al tratamiento, Helicobacter pylori.

\section{SUMMARY}

Objective: To evaluate the rate of eradication and bacterial resistance to treatment for Helicobacter pylori infection in patients at the Apoyo-Pichanaki Hospital in the year 2018. Material and methods: It corresponds to a descriptive, retrospective and cross-sectional study, using a sample of 327 clinical histories of patients with Helicobacter pylori infection, from January to December 2018, using the document analysis technique and the instrument the data record. Results: The eradication rate for Helicobacter pylori infection in patients of the ApoyoPichanaki Hospital was 91.4\%, with optimal first-line therapeutic regimen with clarithromycin $500 \mathrm{mg}$, amoxicillin $1 \mathrm{~g}$ and omeprazole $20 \mathrm{mg}$ every 12 hours for 14 days, the highest rate being eradication in females with $60.9 \%$ and only $39.1 \%$ in males. The highest bacterial resistance was $25 \%$ for ages 44 to 48 years and for females, $8.6 \%$ of bacterial resistance was found. Conclusions: It has been found an eradication rate for Helicobacter pylori of 91.4\%, and $8.6 \%$ bacterial resistance to the first and second line of treatment used for the eradication of the infection.

KEYWORDS: Eradication rate, treatment resistance, Helicobacter pylori.

\footnotetext{
Facultad de Ciencias de la Salud Escuela Profesional de Enfermería, Universidad Privada De Huancayo Franklin Roosevelt. Huancayo, Perú.

a Bachiller; ${ }^{\mathrm{b}}$ Docente, $\mathrm{Mg}$.
} 


\section{INTRODUCCIÓN}

La infección por Helicobacter pylori es un hallazgo frecuente en la población general, siendo su prevalencia mayor en personas que padecen patologías gastrointestinales, principalmente úlcera péptica (UP) y gastritis crónica (1).

Hasta 1983 la secreción ácida del estómago se consideraba el principal factor causal de la úlcera duodenal, por ello el tratamiento de elección eran los fármacos antisecretores. Así, a la cimetidina le siguieron otros antagonistas $\mathrm{H} 2$ (ranitidina, famotidina, nizatidina) y los fármacos inhibidores de la bomba de protones (omeprazol, lansoprazol). Pero, aunque estos medicamentos supusieron un avance no lograron reducir el número de recidivas ulcerosas (2).

Los seres humanos son el único reservorio importante del Helicobacter pylori. Es una bacteria que por lo general se adquiere en la infancia; los niños pueden adquirir el microorganismo de sus padres (más a menudo de la madre) (3).

La adquisición o desaparición de Helicobacter pylori en la edad adulta es poco común. Otros factores de riesgo importantes para la colonización por Helicobacter pylori son el hacinamiento y las malas condiciones de higiene en la infancia. Debido a las diferentes vías de transmisión, por ejemplo; persona a persona, fecal-oral e incluso oral-oral, es una bacteria que puede colonizar con facilidad al ser humano (4).

La infección por Helicobacter pylori es probablemente la infección más frecuente en el hombre, calculándose que aproximadamente el $50 \%$ de la población mundial está infectada por esta bacteria. No obstante, tan sólo el $15 \%$ de las personas infectadas desarrolla una enfermedad en relación con esta infección. Hoy en día se acepta que este microorganismo está relacionado con la gastritis crónica activa, la úlcera péptica (tanto gástrica como duodenal), el adenocarcinoma gástrico y el linfoma gástrico tipo MALT (tejido linfoide asociado a mucosas). Se ha postulado también su relación con la dispepsia funcional, la cardiopatía isquémica, algunas enfermedades dermatológicas (rosácea y urticaria), el retraso del crecimiento en el niño, etc.; sin embargo, estas relaciones no están demostradas (5)

Todos los pacientes infectados por Helicobacter pylori presentan una gastritis histológica, la cual está presente también en el 95\% de los pacientes con una úlcera duodenal y en el $80 \%$ de los pacientes con una úlcera gástrica. Se calcula que el $15 \%$ de los pacientes con una gastritis desarrollan una enfermedad ulcerosa a lo largo de su vida (5).

Además, el hecho de que el Helicobacter pylori se protege del ácido al estar inmerso en la capa de moco, la cual actúa como una barrera que dificulta la exposición de la bacteria a los antibióticos (5).

Un problema importante en la erradicación del Helicobacter pylori es su capacidad de resistencia a diferentes fármacos bajo diversas condiciones.

Se han probado múltiples esquemas para el tratamiento de Helicobacter pylori, pero para considerar un régimen de tratamiento efectivo el consenso Mastricht-III establece que debe alcanzar una tasa de éxito en erradicación de $80 \%$, sin embargo, se reconoce la resistencia a la claritromicina y al metronidazol, como un problema cada vez más frecuente en diversos países y se mantenía en niveles que no influían en el éxito terapéutico.

Helicobacter pylori es la bacteria descrita más recientemente que ha causado mayor revuelo a nivel mundial en medicina, pues se considera que afecta a más del $50 \%$ de la población del globo, con una prevalencia mayor en los países en vías de desarrollo que en los desarrollados. Su importancia ha sido tal, que a menos de dos décadas de su descubrimiento ya se conoce la secuencia de su genoma, se ha descrito una pléyade de factores de virulencia y se acepta su participación en la causalidad de las gastritis, úlceras pépticas e incluso se asocia con algunos tipos de cáncer gástrico (6).

La infección por Helicobacter pylori es la causa fundamental de la enfermedad ulcerosa gastroduodenal y constituye un cofactor primordial en el desarrollo del adenocarcinoma y linfoma gástricos. El tratamiento erradicado de Helicobacter pylori ha supuesto una auténtica revolución en la gastroenterología al permitir no solamente la cicatrización de la úlcera péptica, sino su curación definitiva (6).

El objetivo de evaluar la tasa de erradicación y resistencia al tratamiento para infección por Helicobacter pylori en pacientes del Hospital ApoyoPichanaki en el año 2018. 


\section{MATERIAL Y METODOS}

Este estudio será realizado tomando en cuenta la revisión de diferentes fuentes de información obtenida de bases de datos confiables de las variables tasa de erradicación y resistencia bacteriana al tratamiento para Helicobacter pylori.

Por la forma como se ha planteado el estudio, el tipo de investigación fue básica.

La población de la investigación estuvo constituida por 1800 pacientes de enero a diciembre del 2018 , con diagnóstico de infecciones por Helicobacter pylori.

\section{Criterios de inclusión}

- Historias clínicas de Pacientes ambulatorios que padecen de infecciones por Helicobacter pylori.

- Historias clínicas de Pacientes ambulatorios que padecen de infecciones por Helicobacter pylori en ambos sexos.

- Historias clínicas de Pacientes ambulatorios que padecen de infecciones por Helicobacter pylori en pacientes mayores de 18 años

- Historias clínicas de Pacientes ambulatorios que padecen de infecciones por Helicobacter pylori y que reciben tratamiento para la enfermedad de manera ambulatoria de los meses de Enero diciembre 2018.

\section{Criterios de exclusión}

- Historias clínicas de Pacientes ambulatorios que padecen de infecciones por Helicobacter pylori que involucra casos clínicos de enfermedad ulcerosa péptica, adenorcacinoma gástrico y linfoma gástrico de bajo grado.

- Historias clínicas de Pacientes ambulatorios que padecen de infecciones por Helicobacter pylori en menores de 18 años.

- Historias clínicas de Pacientes que no padecen infección por Helicobacter pylori de los meses de Enero - diciembre 2018.

La muestra fue obtenida a partir de aquellas Historias clínicas de pacientes que padecen de Helicobacter pylori.

Para determinar el tamaño de la muestra, se hizo uso de la fórmula del tamaño de la muestra de poblaciones finitas con un nivel de confiabilidad del $95 \%$, con un margen de error del $5 \%$ donde se desconocen los parámetros poblacionales
Para la recolección de la información se utilizó un proceso planeado paso a paso, para que de forma coherente se puedan obtener resultados que contribuyan favorablemente al logro de los objetivos propuestos. Para cumplir esta investigación se recopiló información primaria y secundaria.

El instrumento utilizado para registrar toda la información durante la investigación fue una Ficha de registro de datos.

\section{RESULTADOS}

En el gráfico 1, se muestra la erradicación positiva del 91,4\% para infección por Helicobacter pylori en pacientes del Hospital de Apoyo - Pichanaki.

En el gráfico 2, se puede apreciar que el régimen terapéutico utilizado para la erradicación del Helicobacter pylori, corresponde a 90,5\% para el esquema terapéutico de claritromicina $500 \mathrm{mg}$, amoxicilina $1 \mathrm{~g}$ y omeprazol $20 \mathrm{mg}$ cada $12 \mathrm{~h}$ mañana y noche por 14 días. Mientras que un $0,9 \%$ recibió el esquema terapéutico de metronidazol $500 \mathrm{mg}$, claritromicina $500 \mathrm{mg}$ y omeprazol 20mg. Existe un $8,6 \%$ de casos no erradicados de pacientes con infección por Helicobacter pylori.

En el gráfico 3, se puede apreciar que un $60,9 \%$ se produce la mayor tasa de erradicación para infección por Helicobacter pylori en pacientes del Hospital Apoyo-Pichanaki en el sexo femenino.

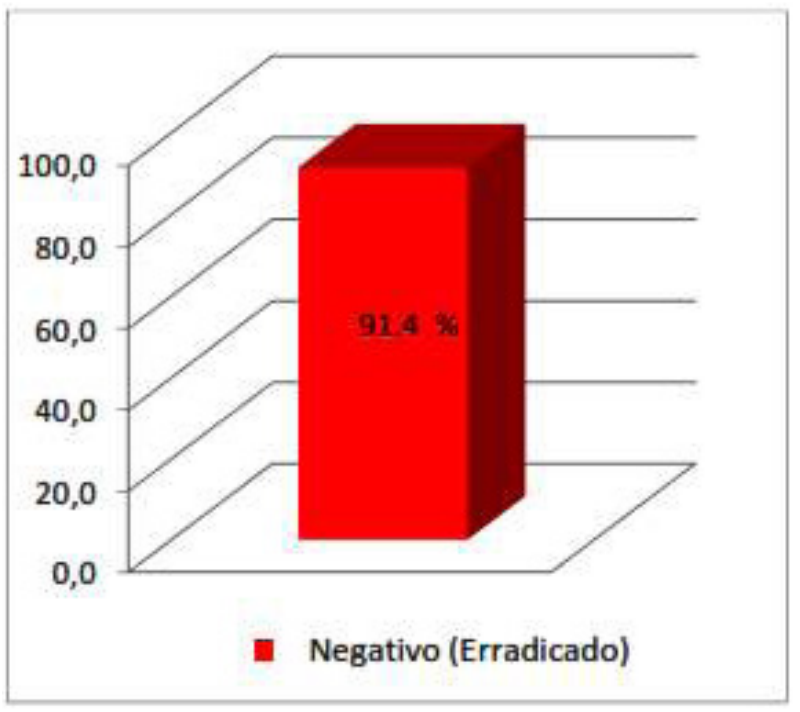

Grafico 1. Tasa de erradicación para infección por Helicobacter pylori en pacientes del Hospital ApoyoPichanaki. 


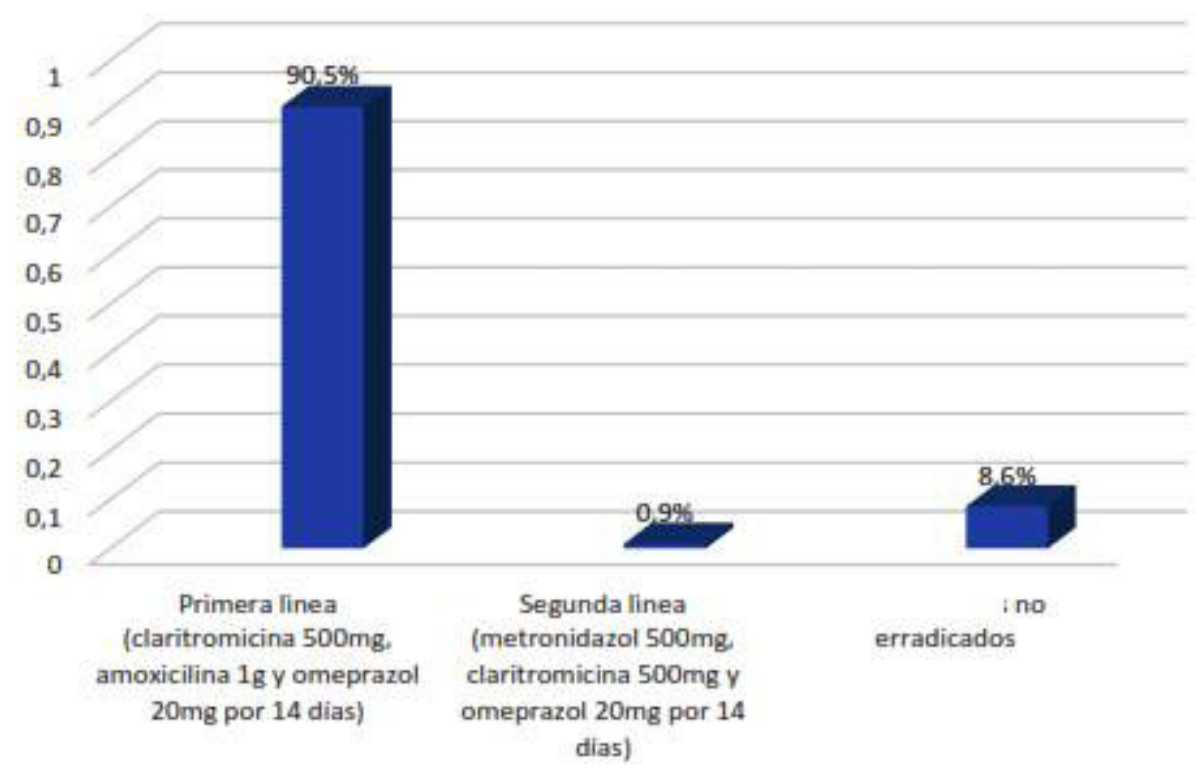

Grafico 2. Regimen terapéutico optimo npara la erradicación del Helicobacter pylori en pacientes del Hospital Apoyo-Pichanaki.

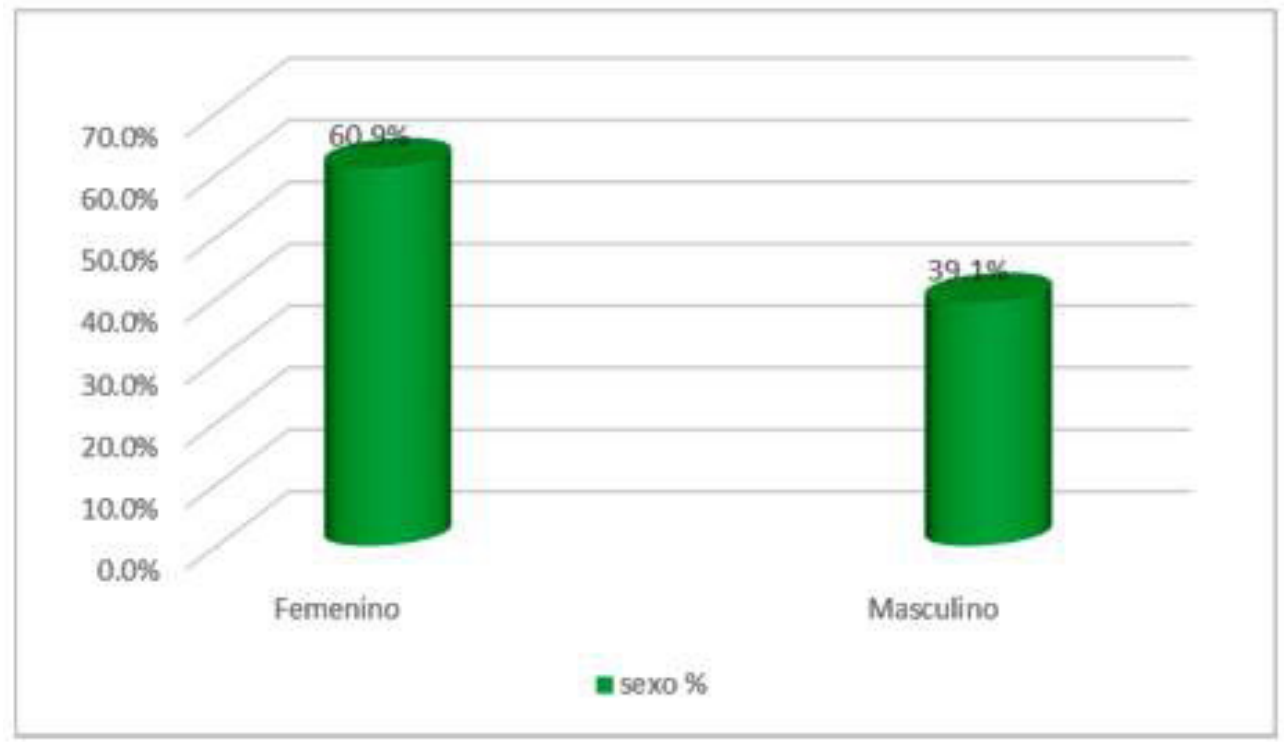

Grafico 3. Sexo en que se produce la mayor tasa de erradicación para infección por Helicobacter pylori en pacientes del Hospital Apoyo-Pichanaki.

Mientras que un 39, 1\%, se produce la mayor tasa de erradicación para infección por Helicobacter pylori en pacientes del Hospital Apoyo-Pichanaki en el sexo masculino.

En la tabla 1, se puede apreciar que existe un 7,1 $\%$, de casos clínicos que se encuentran entre las edades de 39 a 43 años y correspondiente al sexo masculino, de los que presentan mayor resistencia bacteriana. Así también se encuentra un 7,1 \% de casos clínicos que se encuentran entre las edades de 44 a 48 años y correspondiente al sexo masculino.

Mientras que existe un $25 \%$ de pacientes con infección por Helicobacter pylori que se encuentran entre las edades de 44 a 48 años y de sexo femenino, 
Tabla 1. Grupo etareo según sexo en que se produce la resistencia bacteriana para infección por Helicobacter pylori en pacientes del Hospital Apoyo- Pichanaki.

\begin{tabular}{ccccc}
\hline Edad & \multicolumn{3}{c}{ Masculino } & \multicolumn{2}{c}{ Femenino } \\
\cline { 2 - 5 } & $\mathbf{n}$ & $\mathbf{\%}$ & $\mathbf{n}$ & $\mathbf{\%}$ \\
\hline 18 a 23 & 0 & 0 & 1 & 3.6 \\
24 a 28 & 0 & 0 & 1 & 3.6 \\
29 a 33 & 0 & 0 & 2 & 7.1 \\
34 a 38 & 1 & 3.6 & 2 & 7.1 \\
39 a 43 & 2 & 7.1 & 3 & 10.7 \\
44 a 48 & 2 & 7.1 & 7 & 25 \\
49 a 53 & 1 & 3.6 & 5 & 17.9 \\
Mayor/igual a 54 & 0 & 0 & 1 & 3.6 \\
TOTAL & $\mathbf{6}$ & $\mathbf{2 1 . 4}$ & $\mathbf{2 2}$ & $\mathbf{7 8 . 6}$ \\
\hline
\end{tabular}

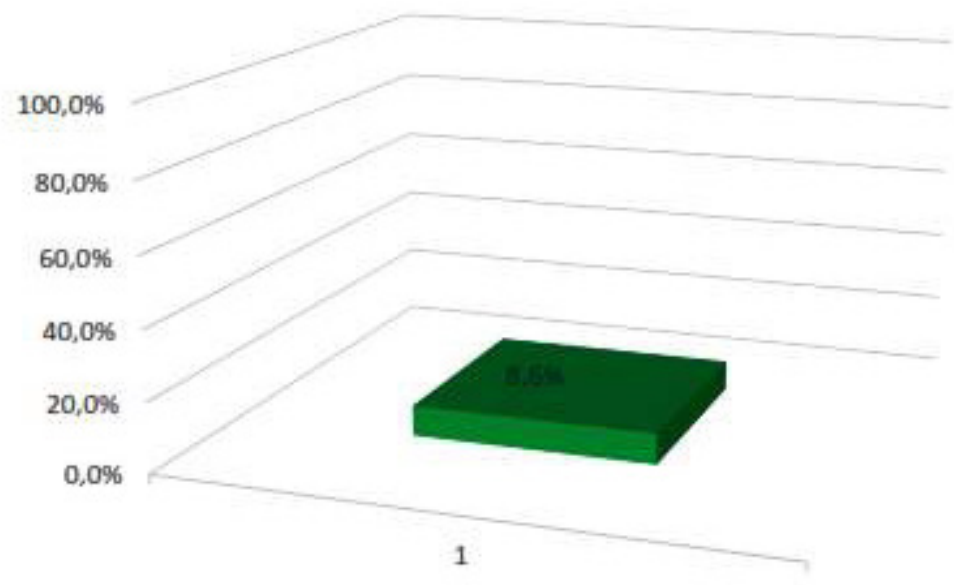

Positivo (No erradicado)

Gráfico 4. Tasa de resistencia al tratamiento para infección por Helicobacter pylori en pacientes del Hospital Apoyo-Pichanaki.

de los que presentan mayor resistencia bacteriana en comparación con el sexo masculino.

En la gráfico 4, se puede apreciar que en un 8,6 $\%$ de la muestra investigada, presentan resistencia al tratamiento farmacológico, para infección por Helicobacter pylori en pacientes del Hospital Apoyo-Pichanaki.

\section{DISCUSIÓN}

Una vez procesado y analizado la información en una muestra de 327 casos de pacientes ambulatorios con infección por Helicobacter pylori, se planteó como objetivo, Evaluar la tasa de erradicación y resistencia bacteriana al tratamiento para infección por Helicobacter pylori en pacientes del Hospital Apoyo-Pichanaki, en el 2018, encontrándose como resultado que se consiguió la erradicación positiva en $91,4 \%$, y la resistencia al tratamiento farmacológico, fue mínima.

De igual forma otro de los objetivos planteados en este estudio fue Determinar la tasa de erradicación para infección por Helicobacter pylori en pacientes del Hospital Apoyo-Pichanaki, encontrándose como resultado, de los 327 pacientes a los que se administró el tratamiento, se consiguió una taza de erradicación 
positiva en $91,4 \%$, lo que se corrobora con el trabajo de León (7) en la tesis titulada Tasa de erradicación del Helicobacter pylori con Tratamiento de Primera Línea en el Hospital II Vitarte en el año 2017, encontrándose como resultado que la tasa de erradicación global fue del $68.9 \%$, de igual situación se corrobora con el trabajo similar de Mompo et al., (2) en el tema titulado Tratamiento con omeprazol, claritromicina y amoxicilina durante una semana. Efectividad y tolerancia en la erradicación de Helicobacter pylori en atención primaria, quien encontró como resultado un elevado porcentaje de erradicación, superior al $80 \%$.

Así también en esta investigación fue importante Determinar el régimen terapéutico óptimo para la erradicación del Helicobacter pylori en pacientes del Hospital Apoyo-Pichanaki, hallándose como resultado que el régimen terapéutico utilizado para la erradicación del Helicobacter pylori, fue en el $90.5 \%$ de pacientes: claritromicina $500 \mathrm{mg}$, amoxicilinalg y omeprazol $20 \mathrm{mg}$, mientras que un $1 \%$ recibió el esquema terapéutico de omeprazol $20 \mathrm{mg}$, metronidazol $500 \mathrm{mg}$ y amoxicilina $1 \mathrm{~g}$ cada 12 horas mañana y noche, lo que se corrobora con el trabajo de León (7), en la tesis titulada Tasa de erradicación del Helicobacter pylori con Tratamiento de Primera Línea en el Hospital II Vitarte en el año 2017, encontrándose como resultado que el régimen terapéutico utilizado fue OCA (Omeprazol $20 \mathrm{mg} / 2$ veces al día + Claritromicina $500 \mathrm{mg} / 2$ veces al día + Amoxicilina $1 \mathrm{~g} / 2$ veces al día) por 10 días, de igual situación se corrobora con el estudio de Mompo Let al (2010)2 en el tema titulado Tratamiento combinación de omeprazol $(20 \mathrm{mg} / 12 \mathrm{~h})$, amoxicilina $(1 \mathrm{~g} / 12 \mathrm{~h})$ y claritromicina $(500 \mathrm{mg} / 12 \mathrm{~h})$ durante una semana tiene una buena eficacia en la erradicación de Helicobacter pylori; sin embargo se contrapone con el trabajo de Lozano (8) titulado Infección por Helicobacter pylori como factor asociado a trombocitopenia. Gastroenterología. Hospital Belén de Trujillo, quien demuestra que un tratamiento doble incluye bien omeprazol a dosis alta más un antibiótico (amoxicilina o claritromicina) o una sal de bismuto más un antibiótico, denominada pauta triple en la asociación de un compuesto de bismuto, metronidazol y un antibiótico, contribuye a la erradicación del Helicobacter pylori.

La mayor tasa de erradicación para infección por Helicobacter pylori en pacientes del Hospital ApoyoPichanaki, corresponde al sexo femenino con un 60,9 $\%$, mientras que en el sexo masculino se ocasiona en el $39,1 \%$, lo que se contrapone al estudio de Lozano (8), en cuyo trabajo encontraron como resultado que los pacientes con infección por Helicobacter pylori, el $61 \%$ fueron de sexo masculino y el $39 \%$ de sexo femenino.

También en este estudio, fue conveniente determinar en qué grupo etáreo, según sexo se produce la resistencia bacteriana para infección por Helicobacter pylori en pacientes del Hospital Apoyo-Pichanaki, hallándose como resultado que de los 28 casos de pacientes con resistencia bacteriana, un $25 \%$ (8), de ellos preferentemente se encuentran entre las edades de 44 a 48 años para el sexo femenino; sin embargo Avellaneda (9) sostiene que la resistencia bacteriana se debe a cambios estructurales y fisiológicos que van a neutralizar los efectos del antibiótico y sin tener influencia la edad ni sexo.

En lo que respecta en evaluar la tasa de resistencia bacteriana para infección por Helicobacter pylori en pacientes del Hospital Apoyo-Pichanaki, se encontró como resultado que un $8,6 \%$ de la muestra investigada, presentan resistencia al tratamiento farmacológico, lo que se contrapone con la investigación de Trespalacios A. et al., (10), quien encontró que encontraron una alta tasa de resistencia a los tres principales antibióticos utilizados en la mayoría de los esquemas exitosos de erradicación de la infección al Helicobacter pylori.

\section{CONCLUSIONES}

En conclusión, la tasa de erradicación para infección por Helicobacter pylori en pacientes del Hospital Apoyo-Pichanaki fue del 91,4\%.

El régimen terapéutico de primera línea para la erradicación del Helicobacter pylori en pacientes del Hospital Apoyo-Pichanaki, fue claritromicina 500mg, amoxicilina $1 \mathrm{~g}$ omeprazol $20 \mathrm{mg}$ cada 12 horas mañana y noche por 14 días.

Según sexo la mayor tasa de erradicación para infección por Helicobacter pylori en pacientes del Hospital Apoyo-Pichanaki, corresponde al sexo femenino en el $60,9 \%$.

El grupo etáreo, según sexo donde se produce la resistencia bacteriana para infección por Helicobacter pylori en pacientes del Hospital Apoyo- Pichanaki se encuentra un $25 \%$, entre las edades de 44 a 48 años y de sexo femenino.

La tasa de resistencia bacteriana para infección por Helicobacter pylori en pacientes del Hospital Apoyo- 
Pichanaki, se encuentra en un $8,6 \%$ de la muestra investigada.

\section{Correspondencia}

Monica Alejandra Calle Vilca

Av. Giráldez 542, Huancayo 12001.

Junin, Perú

\section{REFERENCIAS BIBLIOGRÁFICAS}

1. Velazco B, Amorocho R. Tratamiento de la infección por Helicobacter pylori asociada a gastritis en niños. Rev Gastroenterol Perú .2002;22(2):159-63.

2. Mompo L, Rams F, Jiménez S, Comet D, Baena J, Sancho A. Tratamiento con omeprazol, claritromicina y amoxicilina durante una semana. Efectividad y tolerancia en la erradicación de Helicobacter pylori en atención primaria. Atención primaria. 1998; 22(8):547-51.

3. Velarde F, Bernaola K. Intervención Educativa sobre factores de riesgo en la gastritis en educación no universitaria Palian.Tesis de Grado.Juancayo, Perú: Universidad Peruana Los Andes; 2016.

4. Huanca KM. Complicaciones de la gastritis en adultos de 20 a 35 años atendidos en el área de consulta externa del hospital "San Vicente de Paul "de la ciudad de pasaje en el año 2012. Tesis de Grado. Machala, Ecuador: Universidad Técnica de Machala;
2014.

5. García E. Prevalencia de Helicobacter pylori en residentes de Casa Hogar nuestros pequeños hermanos. Tesis de Grado. Guatemala: Universidad Rafael Landívar;2014.

6. Stasi R, Satparwari A, Segal J, Osborn J, Evangelista $\mathrm{M}$, Cooper N. et al. Efectos de la erradicación de la infección por Helicobacter pylori en pacientes con púrpura trombocitopénica inmune: una revisión sistemática. Sangre .2009; 113: 1231-40.

7. León DA. Tasa de Erradicación del Helicobacter pylori con Tratamiento de Primera Línea en el Hospital II Vitarte en el Año 2017.Tesis de Grado. Perú: Universidad Privada San Juan Bautista; 2017.

8. Quispe F. Infección por Helicobacter pylori como factor asociado a trombocitopenia. Gastroenterología. Hospital Belén de Trujillo.Tesis de Grado. Trujillo, Perú: Universidad Privada Antenor Orrego;2016.

9. Hernández R, Fernández C, Bautista P. Metodología de la investigación 6ta ed. Ciudada de México: Mc Graw-Hill; 2014.

10. Tresalacios A. Investigación Científica en Ciencias de la Salud. Ciudad de Mexico: Interamericana S.A;2010.

Recibido: $15 / 11 / 2019$

Aceptado: 06/06/2020 